\title{
Motor Learning and the Cerebellum
}

\author{
Chris I. De Zeeuw ${ }^{1,2}$ and Michiel M. Ten Brinke ${ }^{1}$ \\ ${ }^{1}$ Department of Neuroscience, Erasmus Medical Center, 3015 GE Rotterdam, The Netherlands \\ ${ }^{2}$ Netherlands Institute for Neuroscience, 1105 BA Amsterdam, The Netherlands \\ Correspondence: c.dezeeuw@erasmusmc.nl
}

Although our ability to store semantic declarative information can nowadays be readily surpassed by that of simple personal computers, our ability to learn and express procedural memories still outperforms that of supercomputers controlling the most advanced robots. To a large extent, our procedural memories are formed in the cerebellum, which embodies more than two-thirds of all neurons in our brain. In this review, we will focus on the emerging view that different modules of the cerebellum use different encoding schemes to form and express their respective memories. More specifically, zebrin-positive zones in the cerebellum, such as those controlling adaptation of the vestibulo-ocular reflex, appear to predominantly form their memories by potentiation mechanisms and express their memories via rate coding, whereas zebrin-negative zones, such as those controlling eyeblink conditioning, appear to predominantly form their memories by suppression mechanisms and express their memories in part by temporal coding using rebound bursting. Together, the different types of modules offer a rich repertoire to acquire and control sensorimotor processes with specific challenges in the spatiotemporal domain.

In the formation of procedural memories, the cerebellum shows at least two types of information coding within its massive neuronal networks (De Zeeuw et al. 2011; Person and Raman 2012; Heck et al. 2013; Yang and Lisberger 2013). Modulation of the average firing rate of neuronal spikes or "rate coding" is most often proposed as the predominant mechanism of information coding used for motor learning (Boyden et al. 2004; Lisberger 2009; Walter and Khodakhah 2009). However, spikes occur at millisecond precision, and their actual timing or "temporal coding" can increase the information content of spike trains and facilitate the entrainment of postsynaptic activity (Markram et al. 1997; De Zeeuw et al. 2011). To a large extent, the coding mechanisms used in the cerebellum for learning and expressing a particular form of motor learning depend on the specific cerebellar module that is controlling the type of behavior involved. The existence of cerebellar modules was discovered half a century ago by Jan Voogd (1964). Simply by studying the thickness of myelinated Purkinje cell axons in the white matter of the cerebellar cortex, Voogd observed distinct differences that were consistently organized in sagittal zones (Fig. 1). Subsequent tracing and immunocytochemical experiments showed that each of these Purkinje cell zones provides an inhibitory projection to a distinct part of the cerebellar nuclei, which in turn inhibits a specific olivary subnucleus (Fig. 2)

Editors: Eric R. Kandel, Yadin Dudai, and Mark R. Mayford

Additional Perspectives on Learning and Memory available at www.cshperspectives.org

Copyright (C) 2015 Cold Spring Harbor Laboratory Press; all rights reserved; doi: 10.1101/cshperspect.a021683

Cite this article as Cold Spring Harb Perspect Biol 2015;7:a021683 


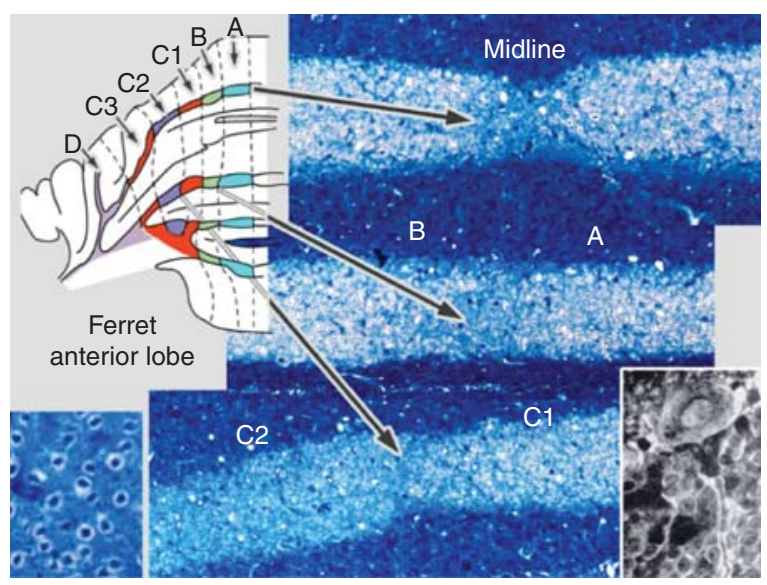

Figure 1. Original identification of Purkinje cell zones in the cerebellar cortex of ferrets using Haggquist staining (based on data from Voogd 1964).

(Groenewegen and Voogd 1977; De Zeeuw et al. 1994, 2011; Ruigrok and Voogd 2000; Ito 2002; Schonewille et al. 2006a). Because the climbing fibers originating from each olivary subnucleus project back to the Purkinje cells of the corresponding cerbellar cortical zone, these circuitries form precisely topographically organized three-element loops (Fig. 3A,B). They are referred to as the olivocerebellar modules and constitute the fundamental building blocks of the cerebellar system. The mossy fiber-parallel fiber system is superimposed in a largely orthogonal fashion on top of the sagittally oriented Purkinje cell zones (Fig. 3C); individual mossy fibers innervate multiple granule cells usually situated in multiple zones and the parallel fibers originating from these granule cells consistently traverse multiple zones in the molecular layer.

Over the past decades, it has gradually become clear that each module is concerned with control of specific tasks, such as execution of limb and finger movements, of trunk movements for balance, of compensatory eye movements about particular axes in space, reflexes of facial musculature, homeostasis of particular autonomic processes, and probably even specific cognitive tasks, such as time-sensitive decision making (De Zeeuw et al. 1994; Ito 2008; Jörntell et al. 2000; Apps and Hawkes 2009; Rahmati et al. 2014). However, it was not until recently that the specific intrinsic properties of different categories of modules emerged (Zhou et al. 2014). Here, we review the intrinsic differences of cerebellar modules and the implications for the coding mechanisms involved in cerebellar motor learning.

\section{INTRINSIC DIFFERENCES AMONG CEREBELLAR MODULES}

The sagittal zones of Purkinje cells in the cerebellar cortex can be identified based on the alternating presence and absence of expression of proteins, such as $5^{\prime}$-nucleotidase, zebrin I (i.e., mabQ113 antigen) and zebrin II (i.e., aldolase $C)$, phospholipase $C \beta 3$ and $\beta 4$, excitatory amino acid transporter 4 (EAAT4), $\mathrm{GABA}_{\mathrm{B} 2}$ receptors, and splice variant $\mathrm{b}$ of the metabotropic glutamate receptor 1 (mGluR1b) (Brochu et al. 1990; Leclerc et al. 1990; Dehnes et al. 1998; Mateos et al. 2001; Wadiche and Jahr 2005; Apps and Hawkes 2009). These zebra-like patterns of protein distribution appear to be present in the cerebellum of all birds and mammals (Brochu et al. 1990; Sillitoe et al. 2003; Chung et al. 2007; Apps and Hawkes 2009; Graham and Wylie 2012), and in many cases they largely correspond to the organization of the olivocerebellar modules (Figs. 2,3A-C) (Sugihara and Shinoda 2004, 2007; Voogd and Ruigrok 2004; Pijpers et al. 2006; Sugihara et al. 2009; Sugihara 2011). For example, zebrin II, EAAT4, and 


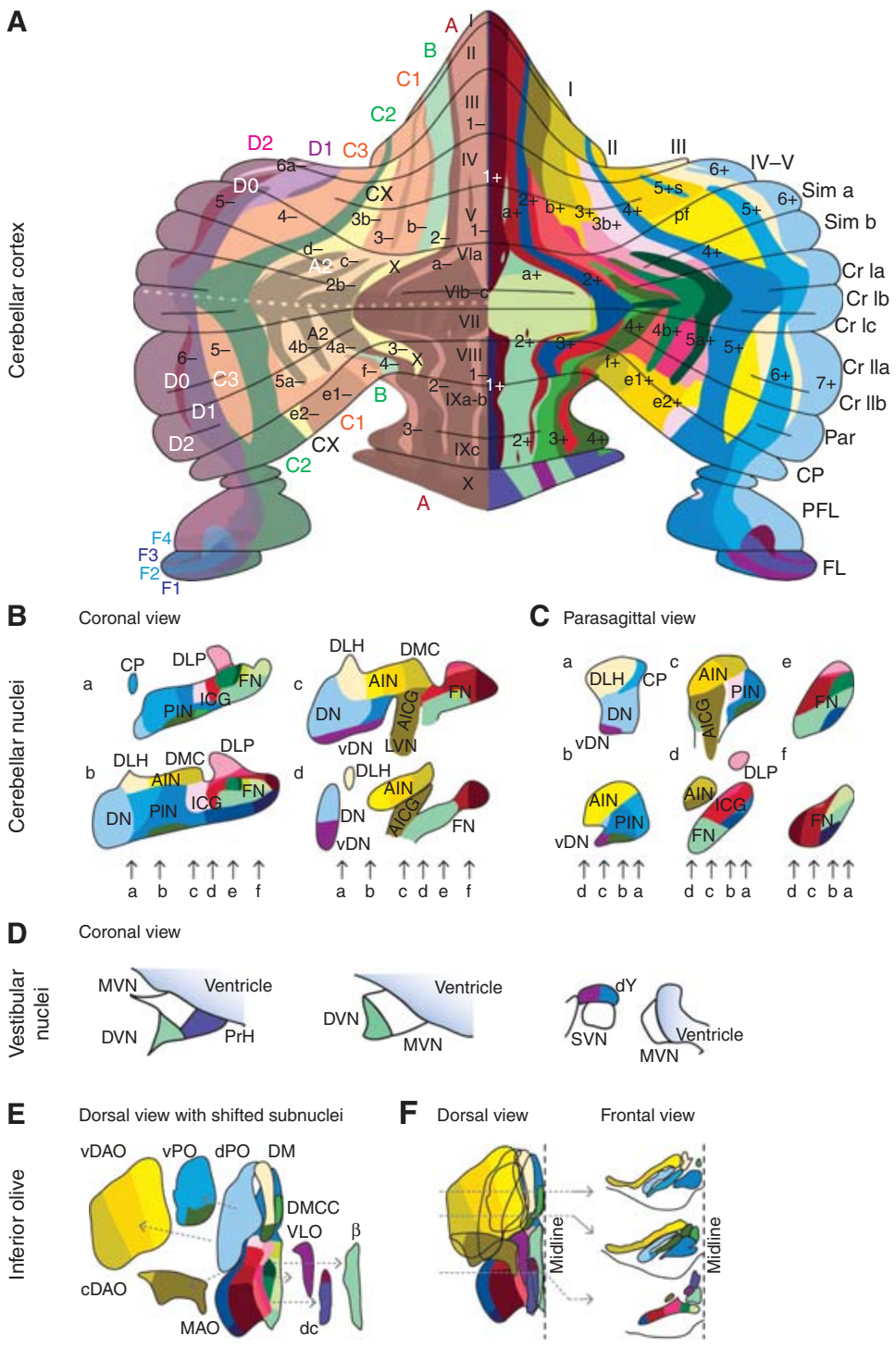

Figure 2. Olivocerebellar modules in mammals. The three-element modules of the olivocerebellar system are formed by a sagittal strip of Purkinje cells in the cerebellar cortex $(A)$, which converge onto a particular set of cerebellar and/or vestibular nuclei $(B-D)$, which, in turn, innervate the subnucleus in the inferior olive $(E, F)$ that provides the climbing fibers to the corresponding strip of Purkinje cells, forming a closed triangular loop. (A) The left part of the cerebellar cortex indicates the original zones described by Voogd (1964), whereas the right part indicates the zebrin related groups described by Sugihara (2011). The color coding used in panels $B-F$ is the same as that used for describing Sugihara's groups in $A$ (i.e., right half), and together they reflect which parts within a particular olivocerebellar module are connected. For reference, we indicated the zebrin-positive strips with dark shading in Voogd's zones on the left. (A) 1-6(a/b/-/+) (see Sugihara and Shinoda 2004, 2007); I-X, lobules I-X; CP, copula pyramidis; Cr I/II, crus I/II of ansiform lobule; FL, flocculus; Par, paramedian lobule; PFL, paraflocculus; Sim, lobulus simplex. $(B, C)$ AICG, anterior interstitial cell group; AIN, anterior interposed nucleus; CP, copula pyramidis; DLH, dorsolateral hump; DLP, dorsolateral protuberance; DMC, dorsomedial crest; (v)DN, (ventral) dentate nucleus; FN, fastigial nucleus; ICG, interstitial cell group; PIN, posterior interposed nucleus. $(D)$ DVN, descending vestibular nucleus; dY, dorsal group Y; MVN, medial vestibular nucleus; $\operatorname{PrH}$, prepositus hypoglossal nucleus; SVN, superior vestibular nucleus. $(E, F) \beta$, subnucleus $\beta$; $(c / v) D A O$, (central/ventral) dorsal accessory olive; dc, dorsal cap; DM, dorsomedial group; DMCC, dorsomedial cell column; MAO, medial accessory olive; (d/v)PO, (dorsal/ventral) principal olive; VLO, ventrolateral outgrowth. Note that the X/CX-zones have only been found at the electrophysiological level (Ekerot and Larson 1982). 


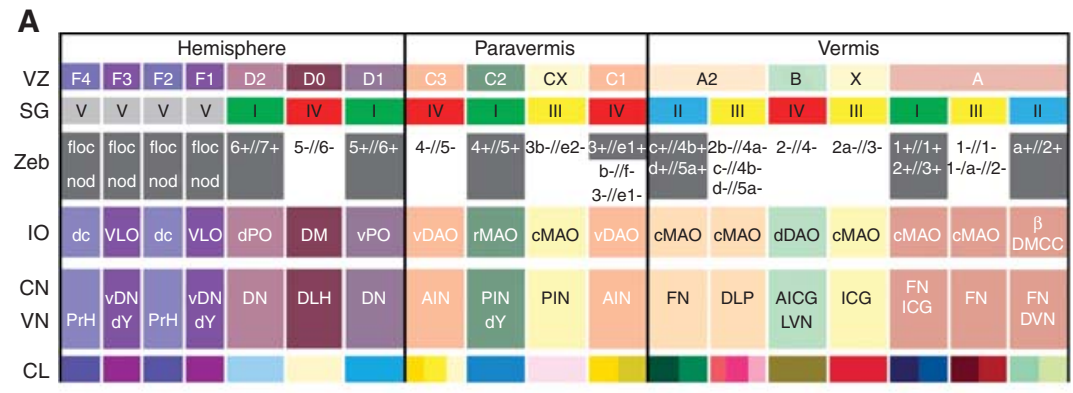

B
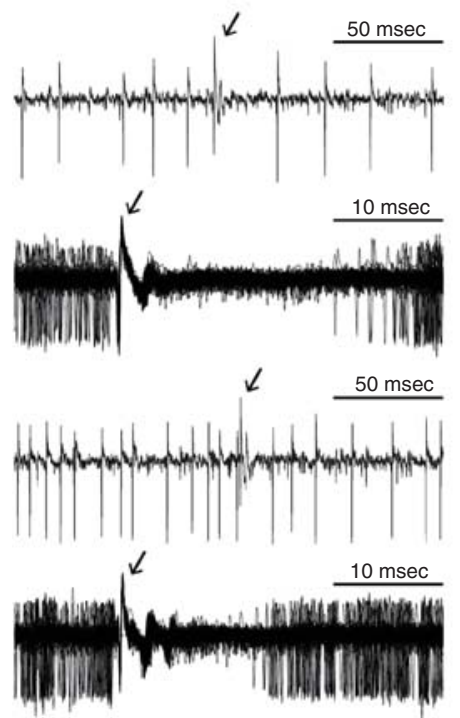

C

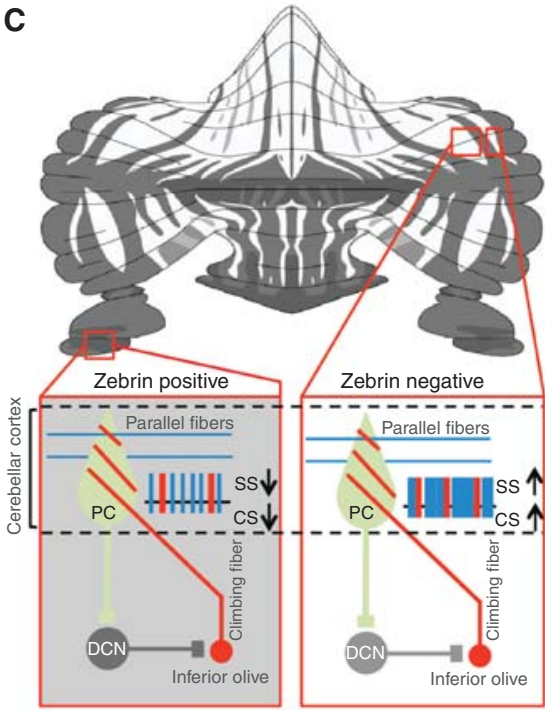

Figure 3. Olivocerebellar modules and Purkinje cell activity in relation to zebrin (II) distribution. (A) The VZ and SG rows refer to the zones and groups of Purkinje cells described by Voogd (1964; VZ) and Sugihara (2011; SG), respectively. The Zeb row indicates which zones and groups are zebrin positive (grey) and zebrin negative (white). The inferior olive (IO) row indicates which subnucleus of the IO is providing climbing fibers to a particular zone/group of Purkinje cells in the cerebellar cortex and collaterals to a particular part of the cerebellar nucleus, depicted in the same column. The $\mathrm{CN}$ and VN row indicates the parts of the cerebellar nuclei $(\mathrm{CN})$ and vestibular nuclei $(\mathrm{VN})$ that are innervated by the strip of Purkinje cells, depicted in the same column. It should be noted that only those vestibular nuclei are indicated that both receive a Purkinje cell input and provide a feedback projection to the inferior olive; because, for example, medial and superior vestibular nuclei do not project to the IO, they are not incorporated in this scheme. In addition, it should be noted that this overview is also incomplete in that some nuclei, such as the dorsomedial cell column (DMCC), may receive inhibitory feedback from multiple hindbrain regions. CL indicates the color legends used for Figure 2. AICG,

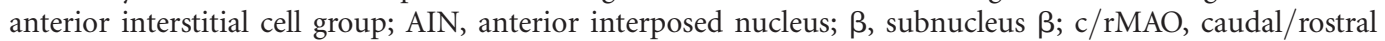
medial accessory olive; dc, dorsal cap; DLH, dorsolateral hump; DLP, dorsolateral protuberance; DM, dorsomedial group; DMC, dorsomedial crest; d/vDAO, dorsal/ventral dorsal accessory olive; DVN, descending vestibular nucleus; d/vPO, dorsal/ventral principal olive; dY, dorsal group Y; floc, flocculus; FN, fastigial nucleus; ICG, interstitial cell group; LVN, lateral vestibular nucleus; nod, nodulus; PIN, posterior interposed nucleus; PrH, prepositus hypoglossal nucleus; vDN, ventral dentate nucleus; and VLO, ventrolateral outgrowth. (B) Examples of raw traces of Purkinje cell activity from zebrin-positive (top panels) and zebrin-negative (bottom panels) zones. Arrows indicate complex spike. (From Zhou et al. 2014; reprinted, with permission, from the authors.) (C) Intramodular connections via deep cerebellar nuclei (DCN) explaining why the complex spike (CS) activity within a module follows the intrinsic differences in simple spike (SS) activity of Purkinje cells (PC). PC and DCN are inhibitory, whereas climbing fibers are excitatory. (From Albergaria and Carey 2014; reprinted under the terms of the Creative Commons Attribution License, which permits unrestricted use and redistribution provided that the original author and source are credited.) 
$\mathrm{GABA}_{\mathrm{B} 2}$ receptors are distributed in Purkinje cells of zones C2, D1, and D2, whereas mGluR1b is prominently expressed in zones $\mathrm{B}, \mathrm{C} 1, \mathrm{C} 3$, and D0, providing a complementary pattern (Mateos et al. 2001; Chung et al. 2007; Apps and Hawkes 2009). Importantly, Zhou and colleagues (2014) recently showed that these distribution patterns determine the intrinsic simple spike activity of Purkinje cells (Fig. 3B,C).

During sensorimotor stimulation and natural behavior, the simple spikes can modulate as a consequence of excitation via the mossy fiberparallel fiber pathway and inhibition via the molecular layer interneurons, but at-rest Purkinje cells show a relatively high level of intrinsic activity, which can reach levels up to $120 \mathrm{~Hz}$. In Purkinje cell zones positive for zebrin II and EAAT4 (referred to as zebrin-positive zones), simple spike firing approximates $60 \mathrm{~Hz}$, whereas in those zones positive for mGluR1b (referred to as zebrin-negative zones), the average firing rate reaches $90 \mathrm{~Hz}$ (Zhou et al. 2014). The intrinsic nature of this difference in simple spike activity at rest cannot be inferred only from the fact that it can be correlated with differential protein expression inside Purkinje cells, but also from the fact that this difference holds when excitatory or inhibitory inputs to Purkinje cells are blocked (Wulff et al. 2009; Galliano et al. 2013a; Zhou et al. 2014). The molecular mechanisms that determine the differences in firing frequencies in the zebrin-positive and zebrin-negative zones have been only partly resolved. Blocking transient receptor potential cation channel type C3 (TRPC3), which can be associated with zebrinnegative Purkinje cells and is required for the mGluR1-mediated slow excitatory postsynaptic currents (EPSCs) (Mateos et al. 2001; Hartmann et al. 2008; Chanda and Xu-Friedman 2011; Kim et al. 2012a,b; Nelson and Glitsch 2012), reduces simple spike activity of Purkinje cells in zebrinnegative, but not zebrin-positive Purkinje cells (Zhou et al. 2014). Thus, tonic activation of mGluR1b by ambient glutamate in zebrin-negative Purkinje cells might lead to opening of their TRPC3-channels and thereby to a relatively high level of simple spike activity (Yamakawa and Hirano 1999; Coesmans et al. 2003; Chanda and Xu-Friedman 2011). In contrast, similar glutamate-dependent increases may be prevented in zebrin-positive Purkinje cells, in which EAAT4 might help to keep glutamate concentrations relatively low (Dehnes et al. 1998; Auger and Attwell 2000; Wadiche and Jahr 2005; cf. Zhou et al. 2014). Downstream from mGluR1, proteins, such as the IP3-receptor (TRPC3 modulator), PLC- $\beta 3 / 4$ (TRPC3 activator), protein kinase $\mathrm{C}(\mathrm{PKC})-\delta$, and NCS-1, play key roles in calcium release from intracellular calcium stores and consequently have electrophysiological impact in line with that of TRPC3. Because several of these proteins are expressed in zebrin-like bands (Barmack et al. 2000; Jinno et al. 2003; Sarna et al. 2006; Hartmann et al. 2008; Becker et al. 2009; Furutama et al. 2010; Wang et al. 2011; Kim et al. 2012a,b), it is possible that this entire pathway contributes to the high simple spike activity of zebrin-negative Purkinje cells. To what extent zebrin itself (i.e., zebrin II or aldolase C) contributes to this pathway is yet unknown, as the impact of its reaction products on simple spike firing is unclear (Zhou et al. 2014).

Whereas the simple spikes are to a large extent determined by the intrinsic activity of Purkinje cells, the all-or-none complex spike activity directly reflects activity in the afferent climbing fibers derived from neurons in the inferior olive (DeZeeuw et al. 2011; Albergaria and Carey 2014; Zhou et al. 2014). Interestingly, at rest, the firing frequency of the complex spikes is aligned with that of the simple spikes in that their firing frequency is also significantly higher in zebrin-negative zones compared with that in zebrin-positive zones (Fig. 3B,C). Thus, even though the complex spike activity copies perfectly the activity of olivary neurons at rest, it still follows the trend of simple spike activity, which is determined by the intrinsic activity of Purkinje cells. How can this come about? This alignment presumably results from a network effect within the olivocerebellar modules engaging the GABAergic neurons in the cerebellar nuclei (Chen et al. 2010; De Zeeuw et al. 2011). Enhanced simple spike activity, as observed in the zebrin-negative modules, will lead to reduced firing of these cerebellar nuclei neurons that inhibit the inferior olivary neurons leading 
to an increase in complex spike activity (De Zeeuw et al. 1988). Because an increase in complex spike activity suppresses simple spike frequency through cerebellar cortical interneurons in the molecular layer (Mathews et al. 2012; Coddington et al. 2013), this network effect ultimately provides an excellent way to mediate homeostasis of activity within the olivocerebellar modules (Fig. 3B,C).

Together, the intrinsically determined simple spike and complex spike activity at rest provide the baseline values around which the Purkinje cells are modulated during natural sensory stimulation, such as that used to induce motor learning. This raises the question as to whether motor learning in the different olivocerebellar modules is also dominated by different plasticity rules mechanisms. Given the baseline firing frequencies, one might expect that zebrin-positive modules with relatively low firing frequencies have ample room for mechanisms of potentiation, whereas zebrin-negative modules showing high simple spike activity could be more prone to suppression. Indeed, Wang and colleagues (2011) found in vivo that the activity of zebrin-positive, but not zebrin-negative, Purkinje cells can be readily enhanced, whereas Wadiche and Jahr (2005) found that, in vitro, the induction of long-term depression (LTD) at the parallel fiber to Purkinje cell synapse can be readily induced in zebrin-negative Purkinje cells in lobule III, but not in zebrin-positive cells in lobule X. Below we will review the dominant learning rules for both a zebrin-positive region, that is, the flocculus of the vestibulocerebellum controlling adaptation of the vestibulo-ocular reflex (Lisberger 1988; Ito 2002; De Zeeuw and Yeo 2005), and a zebrin-negative region, that is, hemispheral lobule VI controlling classical eyeblink conditioning (Hesslow 1994a,b; Thompson and Steinmetz 2009; Boele et al. 2010; Mostofi et al. 2010).

\section{MOTOR LEARNING IN A ZEBRIN-POSITIVE MODULE: ADAPTATION OF THE VESTIBULO-OCULAR REFLEX}

The flocculus, like the nodulus of the vestibulocerebellum, is virtually completely zebrin posi- tive, and indeed its Purkinje cells fire at an average of $\sim 60 \mathrm{~Hz}$ at rest (Fig. 3B). It contains five zones, one for controlling compensatory head movements (extension of the C2 zone) and four for controlling compensatory eye movements about different axes in space (extension of D1-D2 zones, but referred to as $\mathrm{F}$ zones) (Fig. 4A) (De Zeeuw et al. 1994; De Zeeuw and Koekkoek 1997; Schonewille et al. 2006a; Voogd et al. 2012). The vestibulo-ocular reflex translates head movement into compensatory eye movement so as to keep the observed image in the center of the visual field. By experimentally moving a subject's head while also moving the visual environment in the same or opposite direction (i.e., in or out of phase), this reflex will prove insufficient or exaggerated, until the new rules are integrated in the compensatory eye movements following a process of adaptation learning. Mechanical or genetic lesions of floccular Purkinje cells severely hamper adaptation of compensatory eye movements (Endo et al. 2009; Gao et al. 2012). Recordings of Purkinje cells in the flocculus of awake behaving mammals during a vestibulo-ocular reflex paradigm in the dark or light show simple spike modulation that correlates well with both maximum head velocity and maximum eye velocity (De Zeeuw et al. 1995). Adapting the reflex using gain-increase or phase-reversal training leads to an increment in the modulation amplitude of simple spikes (Clopath et al. 2014; K Voges and CI De Zeeuw, pers. comm.), whereas impairing the modulation amplitude of simple spikes by genetically attenuating the parallel fiber to Purkinje cell synapse leads to a reduction in the peak of simple spike modulation as well as in the adaptation and consolidation of the reflexive compensatory eye movements (Fig. 4BE) (Galliano et al. 2013a).

Moreover, stimulating simple spike activity of Purkinje cells either pharmacologically or optogenetically leads to an increase in the excitatory phase of the modulation amplitude of the simple spikes as well as an increase in the gain of compensatory eye movements (van der Steen and Tan 1997; De Zeeuw et al. 2004; Nguyen-Vu et al. 2013). Thus, in line with the data obtained by Wang and colleagues (2011) 
A

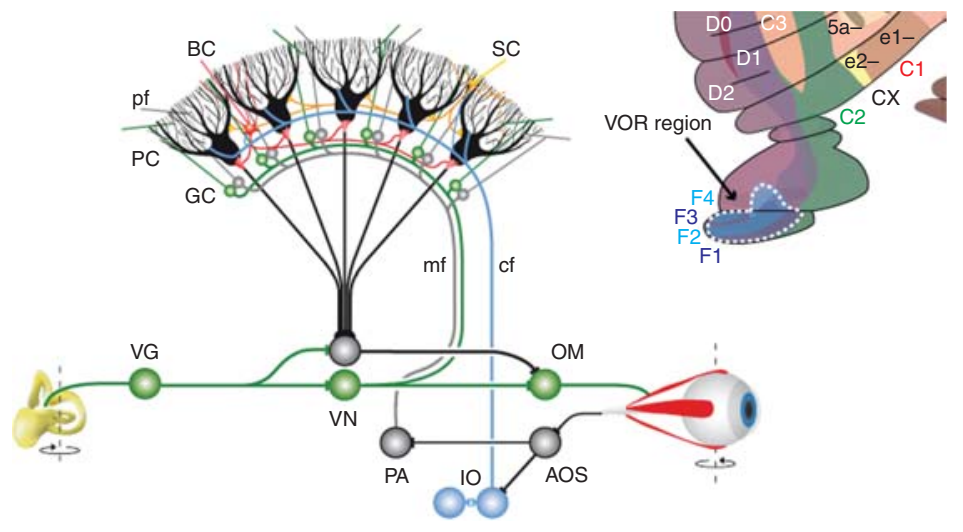

B

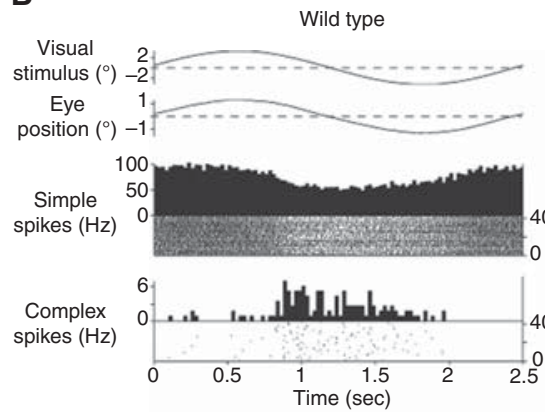

C

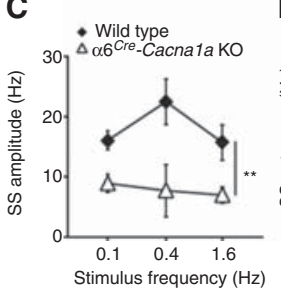

D

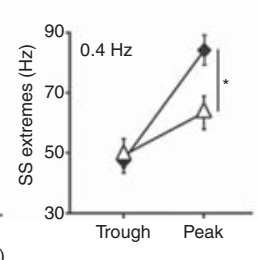

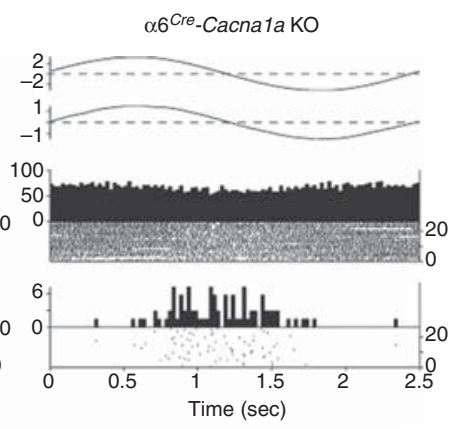

E

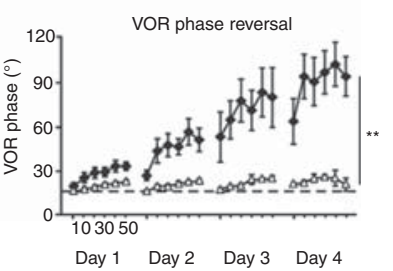

Figure 4. Circuit of the vestibulo-ocular reflex and prominent role of modulation amplitude. $(A)$ The vestibuloocular reflex (VOR) is mediated by the three-neuron arc of Lorente de No in the brainstem. When the head rotates, the vestibular signals from the semicircular canals are transferred by the vestibular ganglion cells (VG) to the second-order vestibular neurons in the vestibular nuclei $(\mathrm{VN})$, which in turn innervate the oculomotor neurons (OMs) driving the eyes to the opposite side. The vestibulocerebellum, which is superimposed on this three-neuron arc, is required to compensate for the delays introduced during input-output processing. To minimize retinal slip during head movements, the accessory optic system (AOS) relays slip signals through the climbing fiber (cf) system to the zebrin-positive Purkinje cells (PC) in floccular zones F1-F4 in the vestibulocerebellar cortex (see inset), where the presence and absence of the climbing fiber activity is integrated with vestibular, optokinetic, and eye movement signals mediated by the mossy fiber (mf)-granule cell (GC) - parallel fiber (pf) pathway. The Purkinje cells in turn can inject well-calibrated, accelerating signals into the vestibular brainstem so as to precisely compensate for the delays. (B) $\alpha 6^{\text {Cre }}$-Cacnala knockout (KO) mice, in which transmission in the vast majority, but not all, of parallel fibers is blocked, show a normal amplitude of their optokinetic reflex when a visual stimulus is given, despite a reduced modulation of their simple spike activity. $(C, D)$ The modulation of the simple spike, but not the complex spike, activity in $\alpha 6^{\text {Cre }}$-Cacnala $\mathrm{KO}$ is reduced over a wide range of frequencies, and these deficiencies are caused by a reduction in the peak of the modulation. (E) VOR phase reversal is a form of VOR adaptation, during which the phase of the VOR is reversed by providing an in-phase optokinetic stimulus that is greater in amplitude than the vestibular stimulus; $\alpha 6^{\text {Cre }}$-Cacnala KO mice have severe problems reversing the phase of their eye movements indicating that mammals have their abundance of GCs and pfs to control motor learning rather than basic motor performance. PA, pontine area; $\mathrm{BC}$, basket cell; SC, stellate cell. (From Galliano et al. 2013a; modified, with permission, from the authors.) 
and Wadiche and Jahr (2005) in other zebrinpositive areas of the cerebellum, these data suggest that strengthening the parallel fiber to Purkinje cell synapse (i.e., through long-term potentiation or LTP) or enhancing the intrinsic excitability of Purkinje cells form the dominating forms of plasticity in the zebrin-positive floccular zones controlling vestibulo-ocular reflex adaptation. Indeed, affecting both forms of potentiation simultaneously by deleting PP2B specifically in Purkinje cells results in deficits in various forms of adaptation of the reflex, such as gain increase, gain decrease, and phase-reversal adaptation (Schonewille et al. 2010). Along the same lines, enhancing Purkinje cell potentiation through an artificial or natural increase of estradiol also improves vestibulo-ocular reflex learning (Andreescu et al. 2007).

In contrast, blocking expression of LTD at the parallel fiber to Purkinje cell synapse by targeting proteins involved in late events of its signaling cascade at the level of GluRs (GluRd7 knockin and GluR2K882A knockin) or related proteins that control their trafficking (PICK1 knockout) does not lead to any obvious deficit in compensatory eye movement learning (Schonewille et al. 2011). These latter experiments indicate that LTD is not essential for vestibuloocular reflex adaptation, but they do not exclude the possibility that LTD contributes to this form of motor learning under physiological conditions. Possibly, the blockage of LTD expression at the parallel fiber to Purkinje cell synapse in the GluRd7 knockin, GluR2K882A knockin, and PICK1 knockout is compensated for by LTP at the parallel fiber to molecular layer interneuron synapse (Jörntell and Ekerot 2002; Gao et al. 2012; Tanaka et al. 2013). Even though motor learning in the zebrin-positive floccular zones may be dominated by postsynaptic and intrinsic potentiation of Purkinje cell activity, the olivocerebellar system is endowed with various distributed forms of plasticity that operate in a synergistic fashion and allow for ample compensation (Gao et al. 2012). This synergy results from the fact that virtually all major forms of plasticity in the cerebellar cortex are controlled by the climbing fibers, and climbing fiber activity is phase-dependent. For example, when an optokinetic pattern moves into temporonasal direction, the subsequent activation of complex spikes in the Purkinje cells of the floccular vertical-axis zones (Fig. 4A) enhances LTD at the parallel fiber to Purkinje cell synapse as well as (on the ipsilateral side) LTP at the parallel-fiber to molecular-layer interneuron synapse and potentiation at the molecular layer interneuron to Purkinje cell synapse (Gao et al. 2014). Yet, when the optokinetic stimulus moves in the opposite direction and the climbing fibers are virtually silent (while being active on the contralateral side), it will induce LTP at the parallel fiber to Purkinje cell synapse and LTD at the parallel-fiber to molecular-layer interneuron synapse (Gao et al. 2012). Together, these climbing-fiber-driven forms of plasticity are so prominent that selectively rerouting the climbing fibers from a contralateral to an ipsilateral projection, while maintaining the laterality of the mossy fiber system, completely reverses modulation of both Purkinje cells' simple spikes and molecular layer interneuron activity (Fig. 5) and induces dramatically ataxic motor behavior, which actually benefits from a cerebellectomy (Badura et al. 2013).

Downstream, it is probably the changes in simple spikes rather than the complex spikes that largely contribute to the changes in eyemovement behavior during adaptation of the vestibulo-ocular reflex (De Zeeuw et al. 2004). Comparison between recordings from floccular target neurons in the vestibular nuclei and floccular Purkinje cells indicates that it is the simple spikes that can relay the prediction signals required for this type of adaptation learning (De Zeeuw et al. 1995; Stahl and Simpson 1995). Indeed, through pure rate coding and plasticity mechanisms in both the flocculus and vestibular nucleus neurons (Nelson et al. 2005), one can explain normal vestibulo-ocular reflex learning and consolidation in regular wild-type animals as well as the specific behavioral phenotypes and simple spike firing characteristics observed in various mutant mice in which either the excitatory or inhibitory inputs to the Purkinje cells are affected (Clopath et al. 2014). 

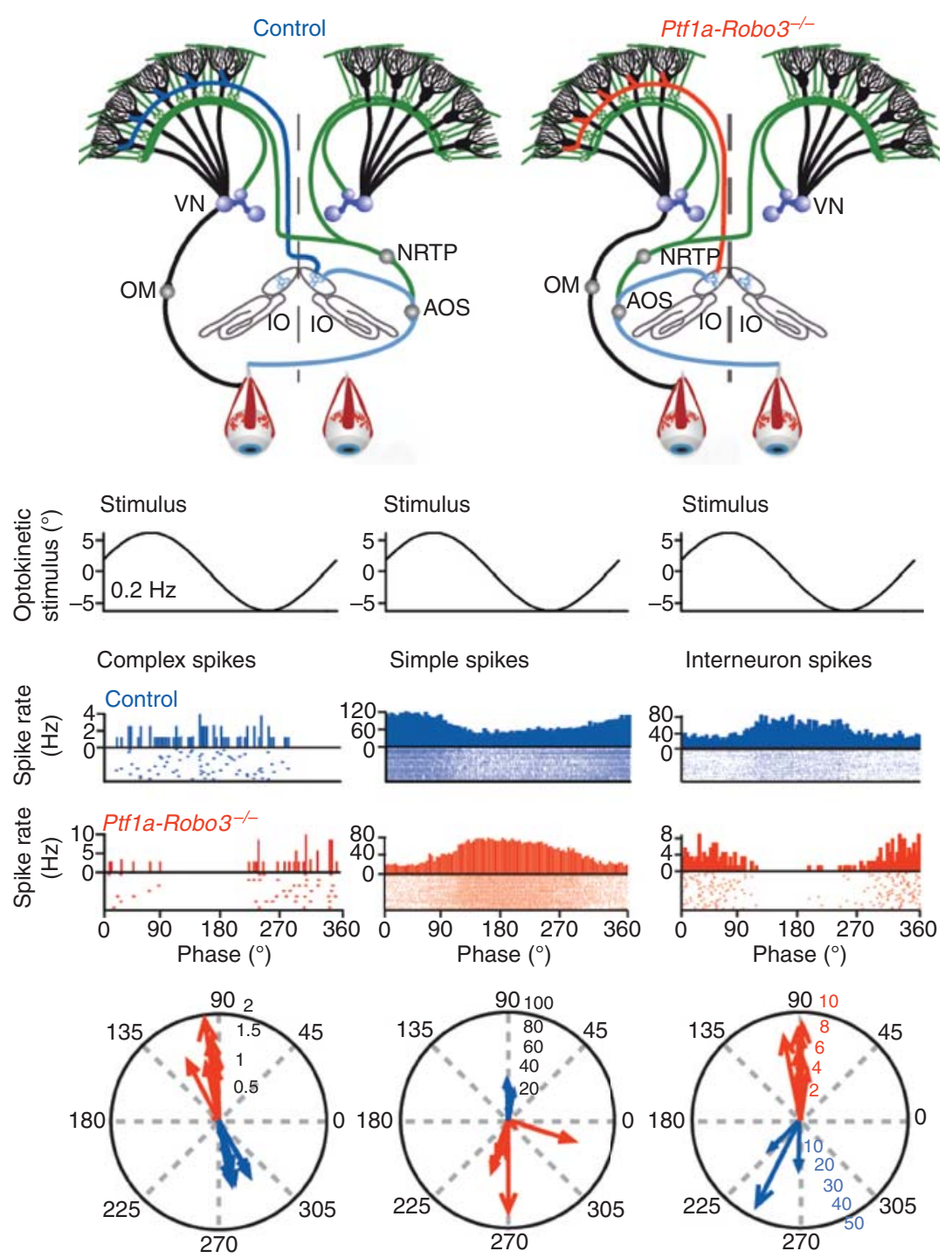

Figure 5. Climbing fibers dominate timing of simple spike firing. Although the complex spikes of Purkinje cells are modulated by activity in the climbing fiber system, the simple spikes are supposed to be largely driven by the mossy fiber system. The frequencies of these two types of spikes are often modulated reciprocally. An increase in complex spikes is associated with a decrease in simple spikes, and vice versa. This reciprocal firing is thought to be essential for motor behavior. Rerouting the climbing fiber system in Ptfla-Robo3 mice from a contralateral (dark blue line in top panel) to a predominantly ipsilateral projection (red line in top panel) does not only reverse the modulation of complex spike activity during natural optokinetic stimulation (see peristimulus-time histograms (PSTHs), raster, and polar plots in left panel), but also that of the simple spike activity (middle panel). Because the laterality of the mossy fiber projection is unaffected (green lines in top panels), these data show that the proper timing of the climbing fiber input is essential for well-coordinated motor performance by controlling the timing of simple spike firing. The phase of molecular layer interneurons is also reversed in the mutants (right panel), which suggests that climbing fibers evoke their effects on simple spike activity via molecular layer interneurons. VN, Vestibular nuclei; NRTP, nucleus reticularis tegmenti pontis; OM, oculomotor neuron; IO, inferior olive; AOS, accessory optic system. (From Badura et al. 2013; modified, with permission, from the authors.) 


\section{MOTOR LEARNING IN A ZEBRIN-NEGATIVE MODULE: EYEBLINK CONDITIONING}

The extensions of the zebrin-negative bands are more prominent in the rostral direction of the cerebellum compared with their caudal counterparts (Sugihara and Shinoda 2004), endowing hemispheric lobule VI, or simplex, with a substantial amount of zebrin-negative Purkinje cells that typically fire at $\sim 90 \mathrm{~Hz}$, subdivided across zones C1, C3, and D0 in particular (Sugihara and Shinoda 2004; Ten Brinke et al. 2014; Zhou et al. 2014). Together with zebrin-positive zone $\mathrm{C} 2$, zones $\mathrm{C} 3$ and $\mathrm{D} 0$ have been shown to respond to periocular stimulation (Hesslow 1994a,b; Mostofi et al. 2010). Through tracer, lesion, and stimulation studies, it has become apparent that cells in C2 are more generally receptive to different kinds of stimulation, whereas $\mathrm{C} 3$ and D0 are specifically engaged with eyelid behavior, with their Purkinje cell output ultimately tying in to the eyelid muscle circuitry (Yeo et al. 1985a,b,c, 1986; Hesslow 1994a,b; Attwell et al. 2001; Boele et al. 2010, 2013; Mostofi et al. 2010).

In the eyeblink-conditioning paradigm, a neutral stimulus leads to an eyeblink response on repeated pairing with a subsequent blinkinducing stimulus (McCormick and Thompson 1984; Yeo et al. 1986; Thompson and Steinmetz 2009; Boele et al. 2010). Eyeblink conditioning has been found to coincide with the development of a marked decrease in Purkinje cell simple spike firing with temporal characteristics similar to those of eyelid conditioned responses (CRs) (Fig. 6) (Albus 1971; Hesslow and Ivarsson 1994; Jirenhed et al. 2007; Ten Brinke et al. 2014). The conditioned stimulus ([CS], e.g., a light or tone) and unconditioned stimulus ([US], e.g., a corneal airpuff), in between which the CR occurs, find their respective physiological correlates in the activity of a myriad of parallel fibers and a single climbing fiber synapsing on the Purkinje cells. The repeated pairing of CS-related parallel fiber input with a subsequent climbing fiber signal, an efferent copy of the eyeblink reflex loop (Fig. 6A), sensitizes the Purkinje cells to the CS in that its simple spike activity gradually diminishes as the conditioning proceeds (Ten Brinke et al. 2014). Importantly, this process is reversible; when the well-timed CS-US pairing is replaced with randomly paired conditioned and unconditioned stimuli, the conditioned eyeblink response and reduction in simple spike response are gradually and concomitantly extinguished (Fig. 6B, middle panel). Following this extinction, simple spike suppression reappears with a reoccurrence of the CRs in the reacquisition process (Fig. 6B, bottom panel). This suppression of simple spike activity in a zebrin-negative module, which necessitates plasticity reducing Purkinje cell activity, juxtaposes starkly with the predominantly simple spikeenhancing forms of plasticity implicated in vestibulo-ocular reflex learning that takes place in zebrin-positive areas.

Historically, the main plasticity mechanism thought to underlie the simple spike suppression during eyeblink conditioning was LTD at the parallel fiber to Purkinje cell synapse (Ito and Kano 1982; Hauge et al. 1998; Koekkoek et al. 2003). Indeed, LTD at this synapse occurs when parallel fibers and climbing fibers are activated conjunctively (Gao et al. 2012), which corresponds well to the situation created by the paired CS-US trials of the eyeblink-conditioning paradigm. However, when parallel fiber to Purkinje cell LTD is blocked following manipulation of the GluR2-AMPA receptors described above (i.e., GluRd7 and GluR2K882A knockin), acquisition of normal CRs is not significantly impaired (Schonewille et al. 2011; see also Welsh et al. 2005). This finding is in line with the fact that most parallel fibers are probably silent to begin with (Brunel et al. 2004; van Beugen et al. 2013) and that at-rest Purkinje cells fire intrinsically at virtually the same rate with intact parallel fiber input as they do without (Cerminara and Rawson 2004; Galliano et al. 2013a; Hesslow 2013). In terms of rate coding, this reduces the direct impact of the few depressed CS-conveying parallel fibers on the overall simple spike suppression to negligible proportions. Along the same line, Hesslow and colleagues found that the duration of the parallel fiber activation, through which a Purkinje cell is trained, does not deter- 
A

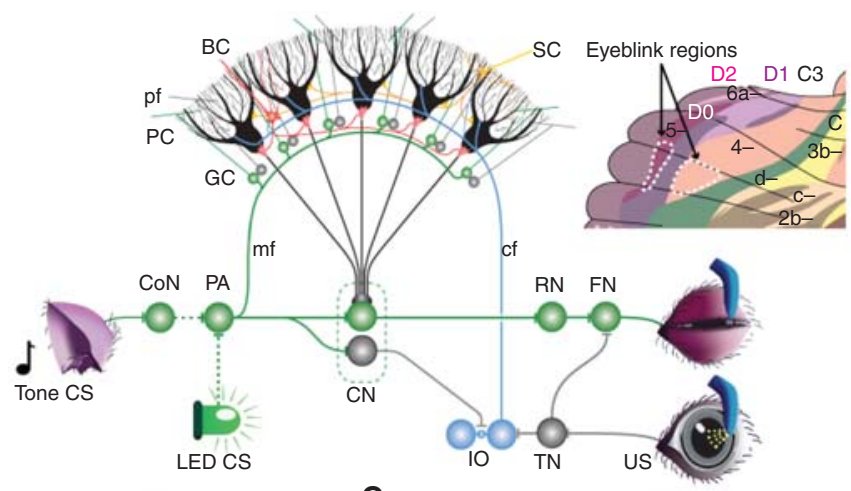

B
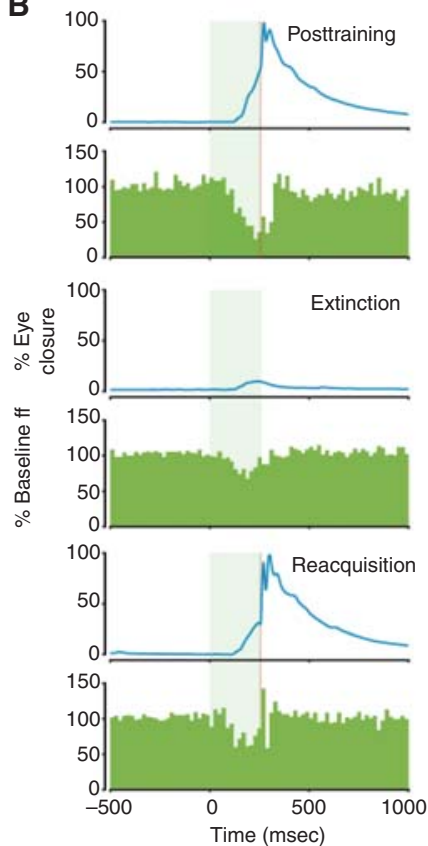

C

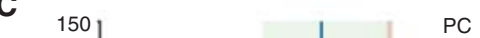

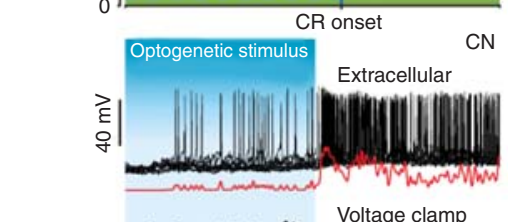
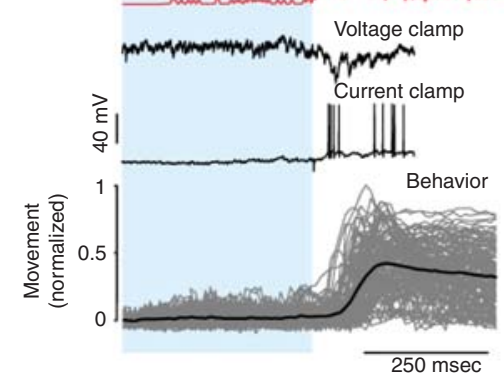

Figure 6. Eyeblink circuit and role of simple spike suppression. (A) During eyeblink conditioning, a conditioned stimulus (CS), such as a tone or LED light, is repetitively paired with an unconditioned stimuli (US), such as an airpuff, to learn a well-timed conditioned response (CR). CS and US sensory information converges at zebrinnegative Purkinje cells (PCs) in D0 and C3 (see inset) through the mossy fiber (mf)-granule cell (GC)-parallel fiber ( pf) pathway and the climbing fibers ( $\mathrm{cfs}$ ) derived from the inferior olive (IO), respectively. Although the mossy fibers relay information on the CS from the pontine area (PA), the climbing fibers mediate efferent copies of signals evoked in the direct eyeblink reflex loop, which is formed by the orbital branch of the trigeminal nerve, trigeminal nucleus (TN), facial nucleus (FN), and eyelid muscle. When a fixed temporal relationship between parallel fiber and climbing fiber activation emerges, the same parallel fiber input starts to evoke a simple spike suppression that disinhibits the cerebellar nuclear $(\mathrm{CN})$ cells, and consequently causes the eyelid to close before the US is about to occur. $(B)$ Example of mean eyelid behavioral traces and simple spike frequency histograms of a mouse Purkinje cell from lobule HVI (zebrin-negative D0 zone) after training, extinction, and reacquisition (top to bottom). Note the concomitant changes in simple spike suppression and amplitude of the CRs. The green and red bands in the background depict CS and US duration, respectively. (C) (Top) Simple spike suppression precedes CR onset (blue line) and covaries with its course (dashed line). (Bottom) A rapid drop in Purkinje cell activity after stopping optogenetic stimulation elicits rebound burst activity in CN neurons (extracellular recording in vivo). The excitatory events in voltage and current clamp recordings of the same cell in vivo following optogenetic Purkinje cell stimulation show that this bursting may be facilitated by climbing and/or mossy fiber collaterals. Ultimately, $\mathrm{CN}$ rebound activity can reliably evoke a behavioral response. The data described under $C$ are obtained from different experiments, but aligned at the same time scale to facilitate understanding of the course of events with respect to each other. CoN, cochlear nucleus; RN, red nucleus. (From Witter et al. 2013; modified, with permission, from the authors.) 
mine the extent and duration of the simple spike suppression (Jirenhed and Hesslow 2011a,b).

Together, these findings suggest that there must be one or more mechanism(s) other than parallel fiber LTD that can actively suppress the simple spike activity when the conditioning signals have started to traverse across the parallel fibers. Two of these potential mechanisms include LTP at the parallel-fiber to molecular-layer interneuron synapse and potentiation at the molecular layer interneuron to Purkinje cell synapse, thereby facilitating inhibitory effects of these interneurons onto the Purkinje cells (Jörntell and Ekerot 2002; Gao et al. 2012). Indeed, blocking both mechanisms in effect by ablating the GABA- $\gamma 2$ receptor specifically in Purkinje cells (Wulff et al. 2009) significantly reduces the percentage and amplitude of CRs (Boele 2014; Ten Brinke et al. 2014). Yet, this inhibitory effect on conditioning behavior is not complete (Boele 2014; Ten brinke et al. 2014), and the impact of gabazine on simple spike suppression in decerebrate ferrets is limited (Johansson et al. 2014), possibly because of extensive ephaptic inhibition at the pinceauforming terminals of the basket cells (Blot and Barbour 2014). If the interneurons are indeed relevant for the simple spike suppression, LTD might still contribute to this process by reducing the excitation in Purkinje cells during the period in which their parallel fiber input also excites the adjacent molecular layer interneurons, evoking the active suppression. Other possibilities for active suppression include LTP at the parallel fiber to Purkinje cell synapse facilitating transmission of the CS signals and driving inhibitory intrinsic Purkinje cell mechanisms through, for example, metabotropic glutamate receptors and downstream PKC-mediated cascades and/or indirectly eliciting CSrelated complex spike activity through the nuclei, which, in turn, adds to direct activation of the molecular layer interneurons (Berthier and Moore 1986; Angaut et al. 1996; Koekkoek et al. 2003; Schonewille et al. 2010; Johansson et al. 2014). In line with the large variety of potential mechanisms, current thoughts about cerebellar learning extend beyond the modification of mere synaptic input of CS signals and are referred to as distributed synergistic plasticity (Gao et al. 2012).

By adopting a suppressive simple spike response, Purkinje cells disinhibit cerebellar interposed nuclear cells, and the subsequent rebound activity in these cells eventually feeds via the red nucleus into the eyelid muscles, effectively closing the eye in well-timed preparation just before the US occurs (Fig. 6C) (Gauck and Jaeger 2000; Boele et al. 2010; Witter et al. 2013). The simple spike suppression starts well before the onset of the conditioned eyeblink response (Ten Brinke et al. 2014), but the extent to which the subsequent increase in cerebellar nuclei firing determines the onset of the eyelid closure or dynamically controls the closure in an online fashion is not known (Sánchez-Campusano et al. 2011). Presumably, the rebound in the activity of cerebellar nuclei neurons following simple spike suppression is facilitated by excitatory inputs from mossy fiber and/or climbing fiber collaterals (Fig. 6C). Indeed, their excitatory inputs can be detected during whole-cell recordings in vivo at precisely the right moment showing coincidence with the internal rebound (Witter et al. 2013).

In contrast to the zebrin-positive modules controlling vestibulo-ocular reflex adaptation, which seem to entail predominantly rate coding, the zebrin-negative module-controlling eyeblink conditioning appears more prone to temporal coding. This is also supported by the fact that synapses of mossy fiber collaterals onto cerebellar nuclei neurons can show LTP following specific sequential activation (Pugh and Raman 2008) and that cerebellar nuclei neurons can be entrained by periods of synchronized simple spike activity at $50-80 \mathrm{~Hz}$ (De Zeeuw et al. 2008, 2011; Person and Raman 2012), that is, the firing rate level that zebrin-negative Purkinje cells acquire during simple spike suppression controlling the conditioned eyeblink response (Fig. 6B,C). Moreover, the mossy fiber collaterals on cerebellar nuclei neurons also show structural preterminal sprouting during conditioning, the amount of which correlates well with the amplitude of the conditioned responses (Boele et al. 2013). 
The notion that the eyeblink-conditioning paradigm involves memory formation at both the cerebellar nuclear and cortical level may explain the considerable savings observed during reacquisition of the learned behavior after extinction (Fig. 6B) (Kehoe 1988; Ohyama et al. 2006). Thus, even though the molecular and cellular machinery behind the active suppression central to the activity in zebrin-negative cerebellar zones still poses questions, the evidence for its functional relation to both plasticity in the cerebellar nuclei and accurate behavioral output as well as for the crucial role of climbing fiber activity at all potential plasticity sites is compelling.

\section{CONCLUDING REMARKS}

The data reviewed here establish the differential intrinsic activity of the different sagittal Purkinje cell zones in the cerebellum and the potential consequences for motor learning. In hindsight, the recent finding by Zhou and colleagues (2014) that the intrinsic simple spike-firing frequencies of zebrin-positive and zebrin-negative Purkinje cells differ dramatically $(60 \mathrm{~Hz}$ vs. $90 \mathrm{~Hz}$ ) could have been predicted by the original study performed 50 years ago by Voogd (1964). Voogd used Haggquist stainings and found that the cerebellar cortex can be divided in zones of Purkinje cells with thin myelinated axons (e.g., zones C2, D1, and D2, which later turned out to be zebrin positive) and Purkinje cells with thick myelinated axons (e.g., zones B, C1, C3, and D0, which turned out to be zebrin negative) (Fig. 1). Indeed, oligodendrogenesis and the thickness of a myelination sheath appear to depend on neuronal activity and firing rate (Gibson et al. 2014). Yet, we are still only just beginning to answer the 50 -year-old question as to what the functional meaning of the cerebellar zones may be. The configuration of these different zones raise the possibility that different encoding schemes are used for motor learning. Indeed the zebrin-positive zones, such as the F1-F4 zones used for vestibulo-ocular reflex adaptation, appear well designed to use mainly potentiation to enhance simple spike firing rate and mediate motor learning through rate-coding mechanisms (Fig. 4). Instead, the zebrin-negative zones, such as the C3 and D0 zones used for eyeblink conditioning, appear optimally designed to use mainly suppression to decrease simple spike firing rate and mediate motor learning, in part, through temporal coding mechanisms downstream in the cerebellar nuclei (Fig. 6), which is supported by input from collaterals of not only mossy fibers but also climbing fibers (Van der Want et al. 1989).

Given the enormous energy consumption of high levels of neuronal activity (Sengupta et al. 2014), one may wonder why a neurobiological system like the cerebellum uses such high levels of intrinsic activity to begin with. There must be obvious benefits preserved throughout evolution (Darwin 1859). Clearly, control of motor learning is one of the prime functions of the cerebellum (Ito 2002; De Zeeuw et al 2011; Gao et al. 2012) and exploiting diversity in intrinsic activity of its main output neurons like Purkinje cells and cerebellar nuclei neurons may benefit the execution of this function, but other regions like the cerebral cortex also have prime roles in learning, including both declarative and procedural memory formation, whereas their main output neurons, pyramidal cells, usually fire at a relatively low firing frequency at rest, preserving energy (Heck et al. 2013; Pouille et al. 2013).

What then is special about the cerebellar system in this regard? The most characteristic feature of all functions of the cerebellum is its ability to control timing at a high resolution. Across periods of hundreds of milliseconds, the cerebellum can regulate and fine-tune signal processing with a precision of $\sim 5 \mathrm{msec}$ (D'Angelo and De Zeeuw 2009; De Zeeuw et al. 2011). This function appears critical for controlling not only relatively simple forms of learning-dependent timing, such as for vestibulo-ocular reflex phase-reversal learning (Fig. 4) and eyeblink conditioning (Fig. 6), but probably also for more complex, timing-sensitive processes involved in cognition and episodic memory formation (Ben-Yakov and Dudai 2011; Rahmati et al. 2014). For example, cerebellar cell-typespecific mouse mutants do not show deficits in general cognitive tasks like Morris water maze, 
fear conditioning, or open field (Galliano et al. 2013b), but the very same mutants start to show phenotypes in decision making when tight temporal response windows are inserted in go/nogo tasks (Rahmati et al. 2014). Likewise, the timing function of the olivocerebellar system is essential when acute reflexes need to be engaged following perturbations (Van Der Giessen et al. 2008). Therefore, it is parsimonious to assess the potential role(s) of high and varying levels of intrinsic Purkinje cell activity in the light of the overall function of the cerebellum in timing.

If one considers the motor domains and functions controlled by the various olivocerebellar modules in mammals (Fig. 2), the picture emerges that slower movements, such as compensatory eye and head movements, are controlled by zebrin-positive modules (e.g., vestibulocerebellum) operating at lower firing frequencies and using rate coding downstream (Clopath et al. 2014), whereas faster movements, such as eyeblink responses or limb activity during locomotion, may depend on zebrin-negative modules (e.g., 5-region in D0 and vermal lobule $\mathrm{V}$, respectively) and fast rebound activity in the cerebellar nuclei (De Zeeuw et al. 2011; Witter et al. 2013). In general, one could state that the presence of intrinsic activity as in zebrin-positive modules allows for on-line modulation in both the excitatory and inhibitory direction with ample opportunity to expand in the excitatory domain during learning (i.e., potentiation) and that an excessive amount of intrinsic activity as in zebrin-negative modules also allows for online modulation in both the excitatory and inhibitory direction, but with ample opportunity to expand in the inhibitory domain (i.e., suppression) engaging fast rebound mechanisms in the nuclei downstream. The latter condition can be considered as a pulled string maintained at a high energy level that can be released on command and evoke very fast effects when needed, such as to protect one's eye with an eyeblink when a dangerous event is approaching.

The design of a system that allows for highly dynamic and precise control of temporal signal processing comes at the cost of continuous high levels of energy consumption, but apparently renders the system with a sufficiently improved survival rate. In this respect, it will be interesting to investigate the intrinsic activity of Purkinje cells during sleep. If the hypothesis described above is correct, one might expect to not waste energy during sleep and bring the cells into a down state (Loewenstein et al. 2005). These down states in Purkinje cells can indeed be induced by anesthetics, whereas they hardly occur in animals operating under physiological circumstances in the awake state (Schonewille et al. 2006b). In addition, it will be interesting to find out to what extent neighboring zebrin-positive and zebrin-negative zones can interact (see also Fig. 3). Interestingly, in the vestibulocerebellum of birds, neighboring zebrin-positive and zebrin-negative modules have been found to respond best to the same pattern of optic flow in 3D space (Graham and Wylie 2012). One could imagine that antagonistic movements characteristic of flying may have different temporal and thereby modulational demands depending on their relation with gravity, engaging the zebrin-positive and -negative modules under different circumstances.

The functional concept of cerebellar modules operating in different firing frequency domains outlined above is based on a dichotomy found in expression of zebrin and related proteins that may control intrinsic simple spike activity. However, even though the differences in firing frequency between zebrin-positive and zebrin-negative modules are highly significant, there is considerable overlap in the ranges of frequencies found (Zhou et al. 2014). This raises the possibility that the encoding schemes used in the various modules are more diverse than depicted here. Indeed, in some microzones, the level of zebrin expression is ambiguous (Mostofi et al. 2010), and the complete proteomics in Purkinje cells is probably sufficiently diverse to even make sagittal strips of single Purkinje cells unique (Voogd et al. 1996). Likewise, it should be noted that one cannot exclude the possibility that suppression and potentiation mechanisms may also take place in zebrin-positive and zebrin-negative modules, respectively (Yang and Lisberger 2013,2014) and that the concomitant encoding schemes during learning may shift ac- 
cordingly, if one switches from a chronic tonic form of learning to a more acute trial-by-trial form of conditioning. In addition, it should be noted that conversion mechanisms may take place at the input stage of both types of modules in that the enhanced input from the semicircular canals to the flocculus may both have to be suppressed during ipsiversive head movements (zebrin-positive zones) and that the active input signaling the conditioned stimulus has to be turned into simple spike suppression during expression of the conditioned response (zebrin-negative zones) (De Zeeuw et al. 2004; Johansson et al. 2014). Therefore, in future studies, it will be important to determine how refined the variety of encoding schemes for cerebellar motor learning really is and to what extent these schemes are related to the dynamics of the paradigm involved. By explaining the encoding schemes for the most widely studied form of motor learning in zebrin-positive modules, that is, adaptation of the vestibulo-ocular reflex in F1-F4, as well as of that in zebrinnegative modules, that is, eyeblink conditioning in C3-D0, this article provides a first step toward unraveling the various encoding schemes that can be used for cerebellar motor learning. Because the zebrin patterns and differences in baseline firing frequencies are consistently present throughout the cerebellar cortex, it is possible that these encoding schemes are applicable to all cerebellar learning functions.

\section{ACKNOWLEDGMENTS}

We thank Bas Koekkoek, Martijn Schonewille, and Elise Buitenhuis Linssen for technical assistance. We thank Izumi Sugihara and Megan Carey for providing the zebrin template and related scheme and allowing us to use it for graphics. Support is provided by the Netherlands Organization for Scientific Research (NWO-ALW, MAGW, ZON-MW), Neuro-Basic, and European Union (ERC-advanced and ERC-POC).

\section{REFERENCES}

Albergaria C, Carey MR. 2014. All Purkinje cells are not created equal. eLife 3: e03285.
Albus JS. 1971. A theory of cerebellar function. Math Biosci 10: $25-61$.

Andreescu CE, Milojkovic BA, Haasdijk ED, Kramer P, De Jong FH, Krust A, De Zeeuw CI, De Jeu MT. 2007. Estradiol improves cerebellar memory formation by activating estrogen receptor $\beta$. J Neurosci 27: 10832-10839.

Angaut P, Compoint C, Buisseret-Delmas C, Batini C. 1996. Synaptic connections of Purkinje cell axons with nucleocortical neurones in the cerebellar medial nucleus of the rat. Neurosci Res 26: 345-348.

Apps R, Hawkes R. 2009. Cerebellar cortical organization: A one-map hypothesis. Nat Rev Neurosci 10: 670-681.

Attwell PJ, Rahman S, Yeo CH. 2001. Acquisition of eyeblink conditioning is critically dependent on normal function in cerebellar cortical lobule HVI. J Neurosci 21: 57155722 .

Auger C, Attwell D. 2000. Fast removal of synaptic glutamate by postsynaptic transporters. Neuron 28: 547-558.

Badura A, Schonewille M, Voges K, Galliano E, Renier N, Gao Z, Witter L, Hoebeek FE, Chedotal A, De Zeeuw CI. 2013. Climbing fiber input shapes reciprocity of Purkinje cell firing. Neuron 78: 700-713.

Barmack NH, Qian Z, Yoshimura J. 2000. Regional and cellular distribution of protein kinase $\mathrm{C}$ in rat cerebellar Purkinje cells. J Comp Neurol 427: 235-254.

Becker EB, Oliver PL, Glitsch MD, Banks GT, Achilli F, Hardy A, Nolan PM, Fisher EM, Davies KE. 2009. A point mutation in TRPC3 causes abnormal Purkinje cell development and cerebellar ataxia in moonwalker mice. Proc Natl Acad Sci 106: 6706-6711.

Ben-Yakov A, Dudai Y. 2011. Constructing realistic engrams: Poststimulus activity of hippocampus and dorsal striatum predicts subsequent episodic memory. J Neurosci 31: 9032-9042.

Berthier NE, Moore JW. 1986. Cerebellar Purkinje cell activity related to the classically conditioned nictitating membrane response. Exp Brain Res 63: 341-350.

Blot A, Barbour B. 2014. Ultra-rapid axon-axon ephaptic inhibition of cerebellar Purkinje cells by the pinceau. Nat Neurosci 17: 289-295.

Boele HJ. 2014. "Learning mechanisms of classical conditioning." PhD thesis, Erasmus University Medical Center, Rotterdam, The Netherlands.

Boele HJ, Koekkoek SK, De Zeeuw CI. 2010. Cerebellar and extracerebellar involvement in mouse eyeblink conditioning: The ACDC model. Front Cell Neurosci 3: 19.

Boele HJ, Koekkoek SK, De Zeeuw CI, Ruigrok TJ. 2013. Axonal sprouting and formation of terminals in the adult cerebellum during associative motor learning. J Neurosci 33: 17897-17907.

Boyden ES, Katoh A, Raymond JL. 2004. Cerebellum-dependent learning: The role of multiple plasticity mechanisms. Annu Rev Neurosci 27: 581-609.

Brochu G, Maler L, Hawkes R. 1990. Zebrin II: A polypeptide antigen expressed selectively by Purkinje cells reveals compartments in rat and fish cerebellum. J Comp Neurol 291: $538-552$.

Brunel N, Hakim V, Isope P, Nadal JP, Barbour B. 2004. Optimal information storage and the distribution of synaptic weights: Perceptron versus Purkinje cell. Neuron 43: $745-757$. 
Cerminara NL, Rawson JA. 2004. Evidence that climbing fibers control an intrinsic spike generator in cerebellar Purkinje cells. J Neurosci 24: 4510-4517.

Chanda S, Xu-Friedman MA. 2011. Excitatory modulation in the cochlear nucleus through group I metabotropic glutamate receptor activation. J Neurosci 31: 7450-7455.

Chen X, Kovalchuk Y, Adelsberger H, Henning HA, Sausbier M, Wietzorrek G, Ruth P, Yarom Y, Konnerth A. 2010. Disruption of the olivo-cerebellar circuit by Purkinje neuron-specific ablation of BK channels. Proc Natl Acad Sci 107: 12323-12328.

Chung S, Zhang Y, Van Der Hoorn F, Hawkes R. 2007. The anatomy of the cerebellar nuclei in the normal and scrambler mouse as revealed by the expression of the microtubule-associated protein kinesin light chain 3 . Brain Res 1140: 120-131.

Clopath C, Badura A, De Zeeuw CI, Brunel N. 2014. A cerebellar learning model of vestibulo-ocular reflex adaptation in wild-type and mutant mice. J Neurosci 34: 7203-7215.

Coddington LT, Rudolph S, Vande Lune P, Overstreet-Wadiche L, Wadiche JI. 2013. Spillover-mediated feedforward inhibition functionally segregates interneuron activity. Neuron 78: 1050-1062.

Coesmans M, Smitt PA, Linden DJ, Shigemoto R, Hirano T, Yamakawa Y, van Alphen AM, Luo C, van der Geest JN, Kros JM, et al. 2003. Mechanisms underlying cerebellar motor deficits due to mGluR1-autoantibodies. Ann Neurol 53: 325-336.

D'Angelo E, De Zeeuw CI. 2009. Timing and plasticity in the cerebellum: Focus on the granular layer. Trends Neurosci 32: $30-40$.

Darwin C. 1859. On the origin of species, pp. 502. John Murray, London.

Dehnes Y, Chaudhry FA, Ullensvang K, Lehre KP, StormMathisen J, Danbolt NC. 1998. The glutamate transporter EAAT4 in rat cerebellar Purkinje cells: A glutamategated chloride channel concentrated near the synapse in parts of the dendritic membrane facing astroglia. $\mathrm{J} \mathrm{Neu-}$ rosci 18: 3606-3619.

De Zeeuw CI, Koekkoek SK. 1997. Signal processing in the C2 module of the flocculus and its role in head movement control. Prog Brain Res 114: 299-320.

De Zeeuw CI, Yeo CH. 2005. Time and tide in cerebellar memory formation. Curr Opin Neurobiol 15: 667-674.

De Zeeuw CI, Holstege JC, Calkoen F, Ruigrok TJ, Voogd J. 1988. A new combination of WGA-HRP anterograde tracing and GABA immunocytochemistry applied to afferents of the cat inferior olive at the ultrastructural level. Brain Res 447: 369-375.

De Zeeuw CI, Wylie DR, DiGiorgi PL, Simpson JI. 1994 Projections of individual Purkinje cells of identified zones in the flocculus to the vestibular and cerebellar nuclei in the rabbit. J Comp Neurol 349: 428-447.

De Zeeuw CI, Wylie DR, Stahl JS, Simpson JI. 1995. Phase relations of Purkinje cells in the rabbit flocculus during compensatory eye movements. J Neurophysiol 74: 2051 2064.

De Zeeuw CI, Koekkoek SKE, van Alphen AM, Luo C, Hoebeek F, van der Steen J, Frens MA, Sun J, Goossens HHLM, Jaarsma D, et al. 2004. Gain and phase control of compensatory eye movements by the flocculus of the vestibulocerebellum, In The vestibular system (ed. Highstein SM, Fay RR, Popper AN), pp. 375-423. Springer, New York.

De Zeeuw CI, Hoebeek FE, Schonewille M. 2008. Causes and consequences of oscillations in the cerebellar cortex. Neuron 58: 655-658.

De Zeeuw CI, Hoebeek FE, Bosman LW, Schonewille M, Witter L, Koekkoek SK. 2011. Spatiotemporal firing patterns in the cerebellum. Nat Rev Neurosci 12: 327-344.

Ekerot CF, Larson B. 1982. Branching of olivary axons to innervate pairs of sagittal zones in the cerebellar anterior lobe of the cat. Exp Brain Res 48: 185-198.

Endo S, Shutoh F, Dinh TL, Okamoto T, Ikeda T, Suzuki M, Kawahara S, Yanagihara D, Sato Y, Yamada K, et al. 2009. Dual involvement of G-substrate in motor learning revealed by gene deletion. Proc Natl Acad Sci 106: 3525 3530.

Furutama D, Morita N, Takano R, Sekine Y, Sadakata T, Shinoda Y, Hayashi K, Mishima Y, Mikoshiba K, Hawkes $\mathrm{R}$, et al. 2010. Expression of the IP3R1 promoter-driven $n l s-l a c Z$ transgene in Purkinje cell parasagittal arrays of developing mouse cerebellum. J Neurosci Res 88: 28102825.

Galliano E, Gao Z, Schonewille M, Todorov B, Simons E, Pop AS, D'Angelo E, van den Maagdenberg AM, Hoebeek FE, De Zeeuw CI. 2013a. Silencing the majority of cerebellar granule cells uncovers their essential role in motor learning and consolidation. Cell Rep 3: 12391251.

Galliano E, Potters JW, Elgersma Y, Wisden W, Kushner SA, De Zeeuw CI, Hoebeek FE. 2013b. Synaptic transmission and plasticity at inputs to murine cerebellar Purkinje cells are largely dispensable for standard nonmotor tasks. $J$ Neurosci 33: 12599-12618.

Gao Z, van Beugen BJ, De Zeeuw CI. 2012. Distributed synergistic plasticity and cerebellar learning. Nat Rev Neurosci 13: 619-635.

Gao Z, vanWoerden GM, Elgersma Y, DeZeeuw CI, Hoebeek FE. 2014. Distinct roles of $\alpha$ - and $\beta$ CaMKII in controlling long-term potentiation of $\mathrm{GABA}_{\mathrm{A}}$-receptor mediated transmission in murine Purkinje cells. Front Cell Neurosci doi: 10.3389/fncel.2014.00016.

Gauck V, Jaeger D. 2000. The control of rate and timing of spikes in the deep cerebellar nuclei by inhibition. J Neurosci 20: 3006-3016.

Gibson EM, Purger D, Mount CW, Goldstein AK, Lin GL, Wood LS, Inema I, Miller SE, Bieri G, Zuchero JB, et al. 2014. Neuronal activity promotes oligodendrogenesis and adaptive myelination in the mammalian brain. Science 344: 1252304.

Graham DJ, Wylie DR. 2012. Zebrin-immunopositive and -immunonegative stripe pairs represent functional units in the pigeon vestibulocerebellum. J Neurosci 32: 1276912779.

Groenewegen HJ, Voogd J. 1977. The parasagittal zonation within the olivocerebellar projection. I: Climbing fiber distribution in the vermis of cat cerebellum. J Comp Neurol 174: 417-488.

Hartmann J, Dragicevic E, Adelsberger H, Henning HA, Sumser M, Abramowitz J, Blum R, Dietrich A, Freichel M, Flockerzi V, et al. 2008. TRPC3 channels are required 
for synaptic transmission and motor coordination. Neuron 59: 392-398.

Hauge SA, Tracy JA, Baudry M, Thompson RF. 1998. Selective changes in AMPA receptors in rabbit cerebellum following classical conditioning of the eyelid-nictitating membrane response. Brain Res 803: 9-18.

Heck DH, De Zeeuw CI, Jaeger D, Khodakhah K, Person AL. 2013. The neuronal code(s) of the cerebellum. J Neurosci 33: $17603-17609$.

Hesslow G. 1994a. Correspondence between climbing fibre input and motor output in eyeblink-related areas in cat cerebellar cortex. J Physiol 476: 229-244.

Hesslow G. 1994b. Inhibition of classically conditioned eyeblink responses by stimulation of the cerebellar cortex in the decerebrate cat. J Physiol 476: 245-256.

Hesslow G, Ivarsson M. 1994. Suppression of cerebellar Purkinje cells during conditioned responses in ferrets. $\mathrm{Neu}$ roreport 5: 649-652.

Hesslow G, Jirenhed DA, Rasmussen A, Johansson F. 2013. Classical conditioning of motor responses: What is the learning mechanism? Neural Netw 47: 81-87.

Ito M. 2002. Historical review of the significance of the cerebellum and the role of Purkinje cells in motor learning. Ann NY Acad Sci 978: 273-288.

Ito M. 2008. Control of mental activities by internal models in the cerebellum. Nat Rev Neurosci 9: 304-313.

Ito M, Kano M. 1982. Long-lasting depression of parallel fiber-Purkinje cell transmission induced by conjunctive stimulation of parallel fibers and climbing fibers in the cerebellar cortex. Neurosci Lett 33: 253-258.

Jinno S, Jeromin A, Roder J, Kosaka T. 2003. Compartmentation of the mouse cerebellar cortex by neuronal calcium sensor-1. J Comp Neurol 458: 412-424.

Jirenhed DA, Hesslow G. 2011a. Time course of classically conditioned Purkinje cell response is determined by initial part of conditioned stimulus. J Neurosci 31: 90709074

Jirenhed DA, Hesslow G. 2011b. Learning stimulus intervals-Adaptive timing of conditioned Purkinje cell responses. Cerebellum 10: 523-535.

Jirenhed DA, Bengtsson F, Hesslow G. 2007. Acquisition, extinction, and reacquisition of a cerebellar cortical memory trace. J Neurosci 27: 2493-2502.

Johansson F, Jirenhed DA, Rasmussen A, Zucca R, Hesslow G. 2014. Memory trace and timing mechanism localized to cerebellar Purkinje cells. Proc Natl Acad Sci 111: $14930-14934$.

Jörntell H, Ekerot CF. 2002. Reciprocal bidirectional plasticity of parallel fiber receptive fields in cerebellar Purkinje cells and their afferent interneurons. Neuron 34: 797806.

Jörntell H, Ekerot C, Garwicz M, Luo XL. 2000. Functional organization of climbing fibre projection to the cerebellar anterior lobe of the rat. J Physiol 522: 297-309.

Kehoe EJ. 1988. A layered network model of associative learning: Learning to learn and configuration. Psychol Rev 95: 411-433.

Kim CH, Oh SH, Lee JH, Chang SO, Kim J, Kim SJ. 2012a. Lobule-specific membrane excitability of cerebellar Purkinje cells. J Physiol 590: 273-288.
Kim Y, Wong AC, Power JM, Tadros SF, Klugmann M, Moorhouse AJ, Bertrand PP, Housley GD. 2012b. Alternative splicing of the TRPC3 ion channel calmodulin/IP3 receptor-binding domain in the hindbrain enhances cation flux. J Neurosci 32: 11414-11423.

Koekkoek SK, Hulscher HC, Dortland BR, Hensbroek RA, Elgersma Y, Ruigrok TJ, De Zeeuw CI. 2003. Cerebellar LTD and learning-dependent timing of conditioned eyelid responses. Science 301: 1736-1739.

Leclerc N, Dore L, Parent A, Hawkes R. 1990. The compartmentalization of the monkey and rat cerebellar cortex: Zebrin I and cytochrome oxidase. Brain Res 506: 70-78.

Lisberger SG. 1988. The neural basis for motor learning in the vestibulo-ocular reflex in monkeys. Trends Neurosci 11: $147-152$.

Lisberger SG. 2009. Internal models of eye movement in the floccular complex of the monkey cerebellum. Neuroscience 162: 763-776.

Loewenstein Y, Mahon S, Chadderton P, Kitamura K, Sompolinsky H, Yarom Y, Hausser M. 2005. Bistability of cerebellar Purkinje cells modulated by sensory stimulation. Nat Neurosci 8: 202-211.

Markram H, Lubke J, Frotscher M, Sakmann B. 1997. Regulation of synaptic efficacy by coincidence of postsynaptic APs and EPSPs. Science 275: 213-215.

Mateos JM, Osorio A, Azkue JJ, Benitez R, Elezgarai I, Bilbao A, Diez J, Puente N, Kuhn R, Knopfel T, et al. 2001. Parasagittal compartmentalization of the metabotropic glutamate receptor mGluR1b in the cerebellar cortex. Eur J Anat 5: 15-21.

Mathews PJ, Lee KH, Peng Z, Houser CR, Otis TS. 2012. Effects of climbing fiber driven inhibition on Purkinje neuron spiking. J Neurosci 32: 17988-17997.

McCormick DA, Thompson RF. 1984. Cerebellum: Essential involvement in the classically conditioned eyelid response. Science 223: 296-299.

Mostofi A, Holtzman T, Grout AS, Yeo CH, Edgley SA. 2010. Electrophysiological localization of eyeblink-related microzones in rabbit cerebellar cortex. J Neurosci 30: 89208934.

Nelson C, Glitsch MD. 2012. Lack of kinase regulation of canonical transient receptor potential 3 (TRPC3) channel-dependent currents in cerebellar Purkinje cells. J Biol Chem 287: 6326-6335.

Nelson AB, Gittis AH, du Lac S. 2005. Decreases in CaMKII activity trigger persistent potentiation of intrinsic excitability in spontaneously firing vestibular nucleus neurons. Neuron 46: 623-631.

Nguyen-Vu TD, Kimpo RR, Rinaldi JM, Kohli A, Zeng H, Deisseroth K, Raymond JL. 2013. Cerebellar Purkinje cell activity drives motor learning. Nat Neurosci 16: 1734 1736.

Ohyama T, Nores WL, Medina JF, Riusech FA, Mauk MD. 2006. Learning-induced plasticity in deep cerebellar nucleus. J Neurosci 26: 12656-12663.

Person AL, Raman IM. 2012. Purkinje neuron synchrony elicits time-locked spiking in the cerebellar nuclei. Nature 481: 502-505.

Pijpers A, Apps R, Pardoe J, Voogd J, Ruigrok TJ. 2006. Precise spatial relationships between mossy fibers and 
C.I. De Zeeuw and M.M. Ten Brinke

climbing fibers in rat cerebellar cortical zones. J Neurosci 26: $12067-12080$.

Pouille F, Watkinson O, Scanziani M, Trevelyan AJ. 2013. The contribution of synaptic location to inhibitory gain control in pyramidal cells. Physiol Rep 1: e00067.

Pugh JR, Raman IM. 2008. Mechanisms of potentiation of mossy fiber EPSCs in the cerebellar nuclei by coincident synaptic excitation and inhibition. J Neurosci 28: 1054910560.

Rahmati N, Owens CB, Bosman LW, Spanke JK, Lindeman S, Gong W, Potters JW, Romano V, Voges K, Moscato L, et al. 2014. Cerebellar potentiation and learning a whiskerbased object localization task with a time response window. J Neurosci 34: 1949-1962.

Ruigrok TJ, Voogd J. 2000. Organization of projections from the inferior olive to the cerebellar nuclei in the rat. JComp Neurol 426: 209-228.

Sánchez-Campusano R, Gruart A, Delgado-Garcia JM. 2011. Dynamic changes in the cerebellar-interpositus/ red-nucleus-motoneuron pathway during motor learning. Cerebellum 10: 702-710.

Sarna JR, Marzban H, Watanabe M, Hawkes R. 2006. Complementary stripes of phospholipase $C \beta 3$ and $C \beta 4$ expression by Purkinje cell subsets in the mouse cerebellum. J Comp Neurol 496: 303-313.

Schonewille M, Luo C, Ruigrok TJ, Voogd J, Schmolesky MT, Rutteman M, Hoebeek FE, De Jeu MT, De Zeeuw CI. 2006a. Zonal organization of the mouse flocculus: Physiology, input, and output. J Comp Neurol 497: 670-682.

Schonewille M, Khosrovani S, Winkelman BH, Hoebeek FE, De Jeu MT, Larsen IM, Van der Burg J, Schmolesky MT, Frens MA, De Zeeuw CI. 2006b. Purkinje cells in awake behaving animals operate at the upstate membrane potential. Nat Neurosci 9: 459-461; author reply 461.

Schonewille M, Belmeguenai A, Koekkoek SK, Houtman SH, Boele HJ, van Beugen BJ, Gao Z, Badura A, Ohtsuki G, Amerika WE, et al. 2010. Purkinje cell-specific knockout of the protein phosphatase PP2B impairs potentiation and cerebellar motor learning. Neuron 67: 618-628.

Schonewille M, Gao Z, Boele HJ, Veloz MF, Amerika WE, Simek AA, De Jeu MT, Steinberg JP, Takamiya K, Hoebeek FE, et al. 2011. Reevaluating the role of LTD in cerebellar motor learning. Neuron 70: 43-50.

Sengupta B, Laughlin SB, Niven JE. 2014. Consequences of converting graded to action potentials upon neural information coding and energy efficiency. PLoS Comput Biol 10: e1003439.

Sillitoe RV, Kunzle H, Hawkes R. 2003. Zebrin II compartmentation of the cerebellum in a basal insectivore, the Madagascan hedgehog tenrec Echinops telfairi. J Anat 203: 283-296.

Stahl JS, Simpson JI. 1995. Dynamics of rabbit vestibular nucleus neurons and the influence of the flocculus. $J$ Neurophysiol 73: 1396-1413.

Sugihara I. 2011. Compartmentalization of the deep cerebellar nuclei based on afferent projections and aldolase $\mathrm{C}$ expression. Cerebellum 10: 449-463.

Sugihara I, Shinoda Y. 2004. Molecular, topographic, and functional organization of the cerebellar cortex: A study with combined aldolase $\mathrm{C}$ and olivocerebellar labeling. $J$ Neurosci 24: 8771-8785.

Sugihara I, Shinoda Y. 2007. Molecular, topographic, and functional organization of the cerebellar nuclei: Analysis by three-dimensional mapping of the olivonuclear projection and aldolase C labeling. J Neurosci 27: 96969710.

Sugihara I, Fujita H, Na J, Quy PN, Li BY, Ikeda D. 2009. Projection of reconstructed single Purkinje cell axons in relation to the cortical and nuclear aldolase $\mathrm{C}$ compartments of the rat cerebellum. J Comp Neurol 512: 282304.

Tanaka S, Kawaguchi SY, Shioi G, Hirano T. 2013. Longterm potentiation of inhibitory synaptic transmission onto cerebellar Purkinje neurons contributes to adaptation of vestibulo-ocular reflex. J Neurosci 33: 1720917220.

Ten Brinke MM, Potters JW, Boele HJ, De Zeeuw CI. 2014. Linking cells to behavior: Purkinje cell electrophysiology during eyeblink conditioning in (transgenic) mice. In 9th Federation of European Neuroscience Societies (FENS), Abstract FENS-3629. Milan, Italy, July 5-9.

Thompson RF, Steinmetz JE. 2009. The role of the cerebellum in classical conditioning of discrete behavioral responses. Neuroscience 162: 732-755.

van Beugen BJ, Gao Z, Boele HJ, Hoebeek F, De Zeeuw CI. 2013. High frequency burst firing of granule cells ensures transmission at the parallel fiber to Purkinje cell synapse at the cost of temporal coding. Front Neural Circuits 7: 95.

Van Der Giessen RS, Koekkoek SK, van Dorp S, De Gruijl JR, Cupido A, Khosrovani S, Dortland B, Wellershaus K, Degen J, Deuchars J, et al. 2008. Role of olivary electrical coupling in cerebellar motor learning. Neuron 58: 599612.

van der Steen J, Tan HS. 1997. Cholinergic control in the floccular cerebellum of the rabbit. Prog Brain Res 114: 335-345.

Van der Want JJ, Wiklund L, Guegan M, Ruigrok T, Voogd J. 1989. Anterograde tracing of the rat olivocerebellar system with Phaseolus vulgaris leucoagglutinin (PHA-L). Demonstration of climbing fiber collateral innervation of the cerebellar nuclei. J Comp Neurol 288: 1-18.

Voogd J. 1964. "The cerebellum of the cat. Structure and fiber connections." PhD thesis, Van Gorcum, Assen, The Netherlands.

Voogd J, Jaarsma DEM. 1996. The cerebellum, chemoarchitecture and anatomy. In Handbook of chemical neuroanatomy (ed. Swanson LW, Björklund A, Hökfelt T), pp. 1-369. Elsevier, Amsterdam.

Voogd J, Ruigrok TJ. 2004. The organization of the corticonuclear and olivocerebellar climbing fiber projections to the rat cerebellar vermis: The congruence of projection zones and the zebrin pattern. J Neurocytol 33: 521.

Voogd J, Schraa-Tam CK, van der Geest JN, De Zeeuw CI. 2012. Visuomotor cerebellum in human and nonhuman primates. Cerebellum 11: 392-410.

Wadiche JI, Jahr CE. 2005. Patterned expression of Purkinje cell glutamate transporters controls synaptic plasticity. Nat Neurosci 8: 1329-1334. 
Walter JT, Khodakhah K. 2009. The advantages of linear information processing for cerebellar computation. Proc Natl Acad Sci 106: 4471-4476.

Wang X, Chen G, Gao W, Ebner TJ. 2011. Parasagittally aligned, mGluR1-dependent patches are evoked at long latencies by parallel fiber stimulation in the mouse cerebellar cortex in vivo. J Neurophysiol 105: 1732 1746.

Welsh JP, Yamaguchi H, Zeng XH, Kojo M, Nakada Y, Takagi A, Sugimori M, Llinas RR. 2005. Normal motor learning during pharmacological prevention of Purkinje cell long-term depression. Proc Natl Acad Sci 102: 1716617171.

Witter L, Canto CB, Hoogland TM, de Gruijl JR, De Zeeuw CI. 2013. Strength and timing of motor responses mediated by rebound firing in the cerebellar nuclei after Purkinje cell activation. Front Neural Circuits 7: 133.

Wulff P, Schonewille M, Renzi M, Viltono L, Sassoe-Pognetto M, Badura A, Gao Z, Hoebeek FE, van Dorp S, Wisden W, et al. 2009. Synaptic inhibition of Purkinje cells mediates consolidation of vestibulo-cerebellar motor learning. Nat Neurosci 12: 1042-1049.

Yamakawa Y, Hirano T. 1999. Contribution of mGluR1 to the basal activity of a mouse cerebellar Purkinje neuron. Neurosci Lett 277: 103-106.
Yang Y, Lisberger SG. 2013. Interaction of plasticity and circuit organization during the acquisition of cerebellum-dependent motor learning. eLife 2: e01574.

Yang Y, Lisberger SG. 2014. Role of plasticity at different sites across the time course of cerebellar motor learning. Neurosci 34: 7077-7090.

Yeo CH, Hardiman MJ, Glickstein M. 1985a. Classical conditioning of the nictitating membrane response of the rabbit. I: Lesions of the cerebellar nuclei. Exp Brain Res 60: 87-98.

Yeo CH, Hardiman MJ, Glickstein M. 1985b. Classical conditioning of the nictitating membrane response of the rabbit. II: Lesions of the cerebellar cortex. Exp Brain Res 60: 99-113.

Yeo CH, Hardiman MJ, Glickstein M. 1985c. Classical conditioning of the nictitating membrane response of the rabbit. III: Connections of cerebellar lobule HVI. Exp Brain Res 60: 114-126.

Yeo CH, Hardiman MJ, Glickstein M. 1986. Classical conditioning of the nictitating membrane response of the rabbit. IV: Lesions of the inferior olive. Exp Brain Res 63: 81-92.

Zhou H, Lin Z, Voges K, Gao Z, Ju C, Bosman LWJ, Ruigrok TJ, Hoebeek FE, De Zeeuw CI, Schonewille M. 2014 Cerebellar modules operate at different frequencies. In 9th Federation of European Neuroscinece Societies (FENS), Abstract FENS-3573, Milan, Italy, July 5-9. 


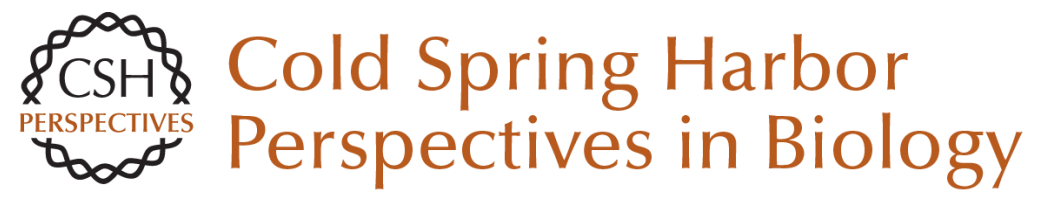

\section{Motor Learning and the Cerebellum}

Chris I. De Zeeuw and Michiel M. Ten Brinke

Cold Spring Harb Perspect Biol 2015; doi: 10.1101/cshperspect.a021683

Subject Collection Learning and Memory

Large-Scale Fluorescence Calcium-Imaging

Methods for Studies of Long-Term Memory in

Behaving Mammals

Pablo Jercog, Thomas Rogerson and Mark J. Schnitzer

Exploring Memory Representations with

Activity-Based Genetics

Mark Mayford and Leon Reijmers

The Origins and Organization of Vertebrate

Pavlovian Conditioning

Michael S. Fanselow and Kate M. Wassum

The Corticohippocampal Circuit, Synaptic

Plasticity, and Memory

Jayeeta Basu and Steven A. Siegelbaum

Motor Learning and the Cerebellum Chris I. De Zeeuw and Michiel M. Ten Brinke

The Striatum: Where Skills and Habits Meet Ann M. Graybiel and Scott T. Grafton

Molecular Genetic Strategies in the Study of Corticohippocampal Circuits

Christopher C. Angelakos and Ted Abel

Nonassociative Learning in Invertebrates John H. Byrne and Robert D. Hawkins
The Role of Functional Prion-Like Proteins in the Persistence of Memory

Kausik Si and Eric R. Kandel

Working Memory: Maintenance, Updating, and the Realization of Intentions

Lars Nyberg and Johan Eriksson

Memory Retrieval in Mice and Men

Aya Ben-Yakov, Yadin Dudai and Mark R. Mayford

Reconsolidation and the Dynamic Nature of

Memory

Karim Nader

Memory Consolidation

Larry R. Squire, Lisa Genzel, John T. Wixted, et al.

Structural Components of Synaptic Plasticity and Memory Consolidation

Craig H. Bailey, Eric R. Kandel and Kristen M.

Harris

Associative Learning in Invertebrates

Robert D. Hawkins and John H. Byrne

The Regulation of Transcription in Memory

Consolidation

Cristina M. Alberini and Eric R. Kandel

For additional articles in this collection, see http://cshperspectives.cshlp.org/cgi/collection/

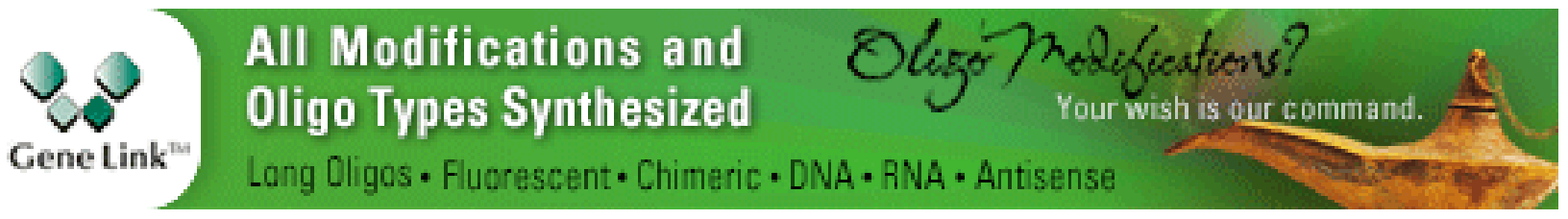

Copyright @ 2015 Cold Spring Harbor Laboratory Press; all rights reserved 